\title{
Subcutaneous Phaeohyphomycosis Cyst Associated with Medicopsis romeroi in an Immunocompromised Host
}

\author{
Alireza Abdolrasouli - Ximena Gonzalo - Anita Jatan • \\ Gordon J. McArthur • Nicholas Francis • Berge S. Azadian • \\ Andrew M. Borman • Elizabeth M. Johnson
}

Received: 5 February 2016/Accepted: 5 May 2016/Published online: 18 May 2016

(C) The Author(s) 2016. This article is published with open access at Springerlink.com

\begin{abstract}
An 88-year-old man, receiving prednisolone for sarcoidosis, presented with a discrete keratotic lesion on the dorsum of his right hand following the placement of an intravenous cannula a month prior to its appearance. Medicopsis romeroi was isolated from the tissue and identified by sequencing the internal transcribed spacer region ITS-1 and the D1-2 fragment of the 28S rDNA gene. Histopathological examination showed fungal hyphae in the internal inflammatory cells layer and within the histocyte-macrophage layer, highly suggestive of deep mycosis. The patient was successfully treated with surgical excision of the cyst. M. romeroi exhibited high MIC values for echinocandin drugs in vitro, but appeared susceptible to newer triazole agents, amphotericin B and terbinafine. This is the first report of a subcutaneous phaeohyphomycotic cyst occurring
\end{abstract}

A. Abdolrasouli $(\bowtie) \cdot X$. Gonzalo · B. S. Azadian Department of Medical Microbiology, 4th Floor East Wing Laboratory Block, Charing Cross Hospital, Imperial College Healthcare NHS Trust, Fulham Palace Road, London W6 8RF, UK

e-mail: ali_reza878@yahoo.com

\section{A. Abdolrasouli}

Fungal Pathogens Immunobiology Laboratory, National

Heart and Lung Institute, Imperial College London,

London, UK

N. Francis

Department of Pathology, Charing Cross Hospital, Imperial College Healthcare NHS Trust, London, UK following the placement of an intravenous cannula. This report highlights the potential role of M. romeroi as an emerging cause of deep, non-mycetomatous infection in immunocompromised patients.

Keywords Medicopsis romeroi .

Phaeohyphomycoses - Mycoses - Antifungal susceptibility testing $\cdot$ Subcutaneous cyst

\section{Introduction}

Phaeohyphomycoses are fungal infections of the skin, or internal organs, caused by darkly pigmented, melanized fungi, which are widely distributed in the environment [1]. In recent years, the incidence of
A. Jatan - G. J. McArthur

Department of Plastic Surgery, Chelsea and Westminster Hospital, Chelsea and Westminster NHS Foundation Trust, London, UK
A. M. Borman · E. M. Johnson
National Mycology Reference Laboratory and National Collection of Pathogenic Fungi, Public Health England, Bristol, UK 
phaeohyphomycosis as well as the diversity of causative organisms has been reported to be increasing globally [2]. Clinically, they are involved in diseases ranging from mild, superficial infections [3] to fatal cerebral phaeohyphomycosis in otherwise healthy individuals [4].

Subcutaneous phaeohyphomycoses is an uncommon localised fungal infection of the deep dermis and subcutaneous tissues caused by a heterogeneous group of dematiaceous fungi [5]. Infection is thought to result from traumatic implantation of the causative fungal organism into the subcutaneous tissue. This form of infection is more common in warm climates and has been reported mainly in immunocompromised hosts [6]. It commonly presents as a single, wellencapsulated, subcutaneous mass or a nodule at the site of previous trauma, commonly on the extremities. The common causative organisms reported include Exophiala, Alternaria, Phialophora, Cladophialophora, and Curvularia/Bipolaris species [5, 7]; however, many others have been implicated on occasion $[8,9]$.

Medicopsis romeroi, formerly known as Pyrenochaeta romeroi, is a rare agent of human black-grain eumycetoma [10, 11]. Recently $M$. romeroi emerged as a cause of deep, non-mycetomatous infections mainly in immunocompromised patients [12-19]. We report here a case of subcutaneous phaeohyphomycotic cyst of the hand caused by $M$. romeroi in an immunocompromised man.

\section{Case Report}

In July 2015, an 88-year-old British man of mixed heritage (Caucasian and Afro-Caribbean) but resident in England most of his life, presented with a 5-month history of a discrete keratotic lesion on the dorsum of his right hand, following the placement of an intravenous cannula a month prior to its appearance. His medical history included chronic obstructive pulmonary disease, gout, benign prostatic hyperplasia, deep venous thrombosis, sarcoidosis and linear $\operatorname{IgA}$ dermatosis. He was on multiple medications for his comorbidities, among which was the immunosuppressant prednisolone. He was treated for leprosy and Bell's palsy in 1994 and denied any recent overseas travel.

Examination confirmed a necrotic lesion $20 \times 12 \mathrm{~mm}$ with a $3 \times 3 \mathrm{~mm}$ well-circumscribed whitened area. The lesion was confined to the skin and subcutaneous tissue with no extension to extensor tendons, bone, lymph node or neurovascular involvement. Cellulitis, tracking lymphangitis and regional lymphadenopathy were absent.

With a differential diagnosis of atypical abscess and epidermal inclusion cyst, the cyst was removed by elliptical excision to subcutis with primary closure; the patient received co-amoxiclav and co-codamol upon discharge. In 10 days of follow up, there was no sign of infection. Histological examination showed an abscess with central neutrophils and prominent surrounding infiltrate of epithelioid macrophages with some giant cells. Periodic acid-Schiff stain showed fungal hyphae in the internal inflammatory cells layer and within the histocyte-macrophage layer (Fig. 1), highly suggestive of deep mycosis. Microscopic examination of the tissue sample with calcofluor white revealed fungal elements, but no granules were observed macroscopically. A dematiaceous mould grew after 10 days of incubation on Sabouraud dextrose agar at both 30 and $37^{\circ} \mathrm{C}$ (Fig. 2). Microscopic examination of the culture showed broad, septate, branched and dark brown hyphae consistent with dematiaceous fungi. No conidia were observed (Fig. 3). With the diagnosis of phaeohyphomycotic cyst, and in view of our patient's immunocompromised state, he was contacted to offer antifungal therapy, which was refused.

For species identification, the internal transcribed spacer region ITS-1 and the D1-2 fragment of the 28S rDNA gene were amplified by PCR using extracted DNA and panfungal primers using previously established protocols [20, 21]. The sequences of the resulting amplicons (European Molecular Biology Laboratory (EMBL) accession nos. LN999520 and LN999521) were both $100 \%$ identical to reference sequences of $M$. romeroi present in public sequence databases, and to the type strain of $M$. romeroi in the National Collection of Pathogenic Fungi (NCPF 2301) housed at the National Mycology Reference Laboratory, Public Health England, Bristol, UK (data not shown). The isolate from the current case has been preserved in inert form in the NCPF with the unique identifier NCPF 7881.

Antifungal susceptibility testing was performed by microbroth dilution according to the Clinical and Laboratory Standards Institute (CLSI) M38-A2 guideline [22]. The minimum inhibitory concentrations 


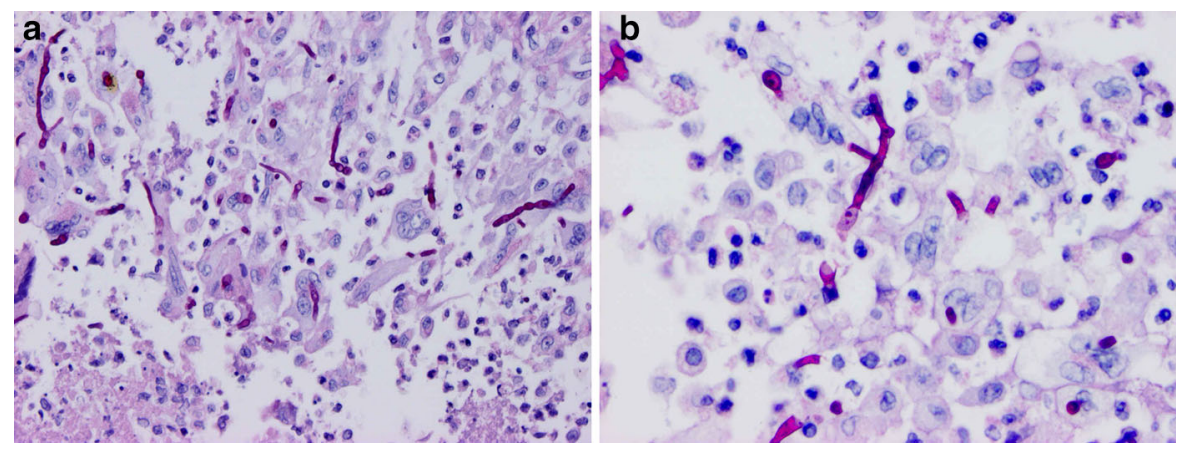

Fig. 1 Fungal hyphae in the internal inflammatory cells layer and within the histocyte-macrophage layer, PAS stain with magnification of $\times 200$ (a) and $\times 400(\mathbf{b})$
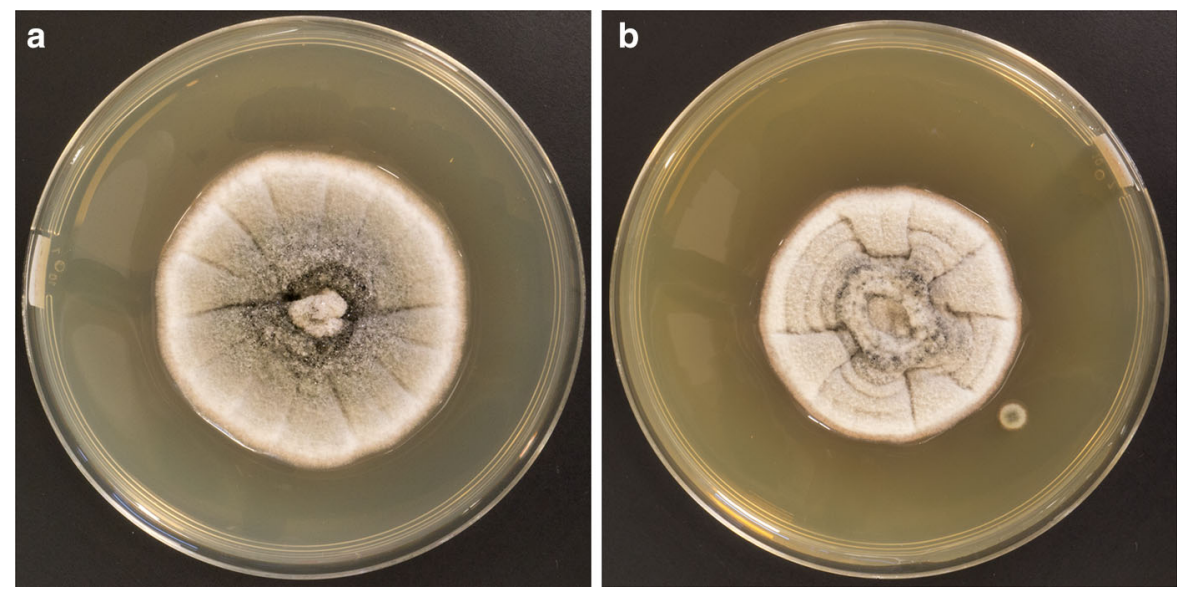

Fig. 2 Colonies of M. romeroi on SDA (a), and malt extract agar (b) after 10 days incubation at $28-30{ }^{\circ} \mathrm{C}$ in dark. Colonies were initially brownish but became olivaceous grey and floccose with age on both culture media

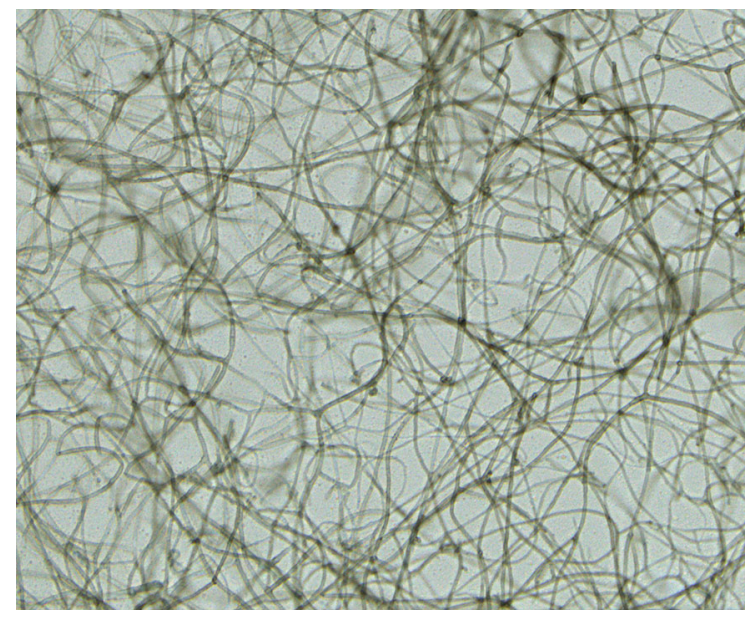

Fig. 3 Broad, septate, branched and dark brown hyphae consistent with dematiaceous fungi. Magnification $\times 400$
(MICs) of antifungal drugs were: amphotericin B $(0.25 \mu \mathrm{g} / \mathrm{ml})$, fluconazole $(>64 \mu \mathrm{g} / \mathrm{ml})$, itraconazole $(0.5 \mu \mathrm{g} / \mathrm{ml})$, voriconazole $(0.5 \mu \mathrm{g} / \mathrm{ml})$, posaconazole $(0.25 \mu \mathrm{g} / \mathrm{ml})$ and terbinafine $(0.125 \mu \mathrm{g} / \mathrm{ml})$. Caspofungin, anidulafungin and micafungin all gave minimum effective concentration (MEC) of $4.0 \mu \mathrm{g} / \mathrm{ml}$.

\section{Discussion}

Phaeohyphomycosis is an uncommon fungal infection, although its incidence has been reported to be on the rise globally $[1,2]$. Most phaeohyphomycosis infections are caused by Exophiala, Alternaria, Cladophialophora, Phialophora or Curvularia/Bipolaris species; however, many others have been implicated on occasion [5, 7]. Infection is most often 
acquired from traumatic implantation of the causative agent into subcutaneous tissue. The usual clinical presentation is the asymptomatic development of a single subcutaneous mass (nodule, cyst or abscess) at the site of prior trauma [6]. M. romeroi is a saprophytic fungus widely distributed worldwide, where it grows on soil and vegetation, particularly in tropical climates. The majority of the previously reported cases have occurred in patients with a history of residence in India, Pakistan and Venezuela [12].

Although the etiological role of $M$. romeroi in black-grain mycetoma is well established [10, 23], it has only recently been recognised as a cause of deep, non-mycetomatous infections [12-17, 19]. In contrast to mycetoma, no discharge or visible grains are present. This could potentially be a relatively new clinical condition presenting as subcutaneous nodule, cyst or abscess caused by this species mostly in immunocompromised patients. Our patient was on long-term prednisolone for sarcoidosis which we believe could potentially contribute to his recent fungal infection with $M$. romeroi. Among the immunosuppressed population, solid organ transplant recipients and patients receiving chronic corticosteroids are at risk for dematiaceous fungal infections $[6,24,25]$. Of note, most cases of subcutaneous phaeohyphomycosis caused by $M$. romeri have been reported among renal transplant recipients $[15,17,19$, 26]. Individual cases have also been described in patients with acute lymphoblastic leukaemia [13], diabetes mellitus [14] or those receiving prolonged immunosuppressant agents [16, 18]. However, cases have been described in previously healthy immunocompetent individuals [12] where cysts are often chronic and relatively asymptomatic.

Subcutaneous phaeohyphomycotic lesions are often surgically excised which is usually curative with no further antifungal therapy [12, 27]. Systemic antifungal therapy is used in patients with refractory or recurrent infections perhaps due to incomplete resection of the lesion. The agents that have most frequently been used include amphotericin B, 5-flucytosine, itraconazole and terbinafine. The newer triazoles have moderate-to-excellent in vitro antifungal activity against dematiaceous moulds and can be given safely for prolonged periods for treatment of phaeohyphumycosis [27].

Information on the antifungal susceptibility of $M$. romeroi is rather limited due to lack of high number of clinical isolates and absence of established breakpoints. In addition, relation between in vitro MIC values and clinical outcome of infection is poorly understood. The available evidence suggests considerable strain-specific variation in MIC values with respect to amphotericin $\mathrm{B}$ and itraconazole, elevated MICs for fluconazole, ketoconazole, and lower MICs for voriconazole $[23,28]$. Our isolate demonstrated a high MIC with fluconazole; however, lower MICs were observed to the newer triazole agents. High MECs observed with the echinocandin group, in agreement with previous reports [23, 28], suggest these agents would not be a good choice for treatment of $M$. romeroi infections. Terbinafine might be efficacious against this fungus.

\section{Conclusion}

This report highlights the potential role of $M$. romeroi as an emerging cause of subcutaneous, phaeohyphomycotic cysts in immunocompromised patients with no travel history to tropical or subtropical areas. Recognition of infections caused by dematiaceous fungi remains challenging as many isolates are difficult to identify by conventional methods and require molecular approaches.

Acknowledgments Written consent was obtained from our patient to publish this case. We thank N. Bartholomew for technical assistance in taking photographs of fungal cultures.

\section{Compliance with ethical standards}

Conflict of interest On behalf of all authors, the corresponding author states that there is no conflict of interest.

Open Access This article is distributed under the terms of the Creative Commons Attribution 4.0 International License (http:// creativecommons.org/licenses/by/4.0/), which permits unrestricted use, distribution, and reproduction in any medium, provided you give appropriate credit to the original author(s) and the source, provide a link to the Creative Commons license, and indicate if changes were made.

\section{References}

1. Revankar SG, Sutton DA. Melanized fungi in human disease. Clin Microbiol Rev. 2010;23(4):884-928.

2. Revankar SG. Phaeohyphomycosis. Infect Dis Clin North Am. 2006;20(3):609-20. 
3. Saunte DM, Tarazooie B, Arendrup MC, De Hoog GS. Black yeast-like fungi in skin and nail: it probably matters. Mycoses. 2012;55(2):161-7.

4. Jabeen K, Farooqi J, Zafar A, Jamil B, Mahmood SF, Ali F, et al. Rhinocladiella mackenziei as an emerging cause of cerebral phaeohyphomycosis in Pakistan: a case series. Clin Infect Dis. 2011;52(2):213-7.

5. Isa-Isa R, Garcia C, Isa M, Arenas R. Subcutaneous phaeohyphomycosis (mycotic cyst). Clin Dermatol. 2012;30(4):425-31.

6. Sutton DA, Rinaldi MM, Sanche SE. Dematiaceous fungi. In: Anaissie EJ, McGinnis MR, Pfaller MA, editors. Clinical mycology, 2nd ed. Churchill Livingstone; 2009. p. 329-54.

7. Bhardwaj S, Capoor MR, Kolte S, Purohit G, Dawson L, Gupta K, et al. Phaeohyphomycosis due to Exophiala jeanselmei: an emerging pathogen in India-case report and review. Mycopathologia. 2016;181(3-4):279-84.

8. Desoubeaux G, García D, Bailly E, Augereau O, Bacle G, De Muret A, et al. Subcutaneous phaeohyphomycosis due to Phialemoniopsis ocularis successfully treated by voriconazole. Med Mycol Case Rep. 2014;5(1):4-8.

9. Agrawal A, Singh SM. Two cases of cutaneous phaeohyphomycosis caused by Curvularia pallescens. Mycoses. 1995;38:301-3.

10. Ahmed SA, van de Sande WWJ, Stevens DA, Fahal A, van Diepeningen AD, Menken SBJ, et al. Revision of agents of black-grain eumycetoma in the order Pleosporales. Persoonia. 2014;33:141-54.

11. Cerar D, Malallah YM, Howard SJ, Bowyer P, Denning DW. Isolation, identification and susceptibility of Pyrenochaeta romeroi in a case of eumycetoma of the foot in the UK. Int J Antimicrob Agents. 2009;34(6):617-8.

12. Badali H, Chander J, Gulati N, Attri A, Chopra R, Najafzadeh MJ, et al. Subcutaneous phaeohyphomycotic cyst caused by Pyrenochaeta romeroi. Med Mycol. 2010;48(5):763-8.

13. Khan Z, Ahmad S, Kapila K, Ramaswamy NV, Alath P, Joseph L, et al. Pyrenochaeta romeroi: a causative agent of phaeohyphomycosis cyst. J Med Microbiol. 2011;60(6):842-6.

14. Yadav S, Agarwal R, Singh S, Goel S. Pyrenochaeta romeroi causing subcutaneous phaeohyphomycotic cyst in a diabetic female. Med Mycol Case Rep. 2015;8:47-9.

15. Thiyagarajan UM, Bagul A, Nicholson ML. A nodulocystic eumycetoma caused by Pyrenochaeta romeroi in a renal transplant recipient: a case report. J Med Case Rep. 2011;5(1):460.

16. Hsiao Y, Chia J, Lu C, Chung W. Molecular diagnosis and therapeutic experience of subcutaneous Pyrenochaeta romeroi infection: a case report and review of the literature. Int J Dermatol. 2013;52:1237-40.

17. Chan YYC, Tan AL, Tan BH. Subcutaneous abscess due to Pyrenochaeta romeroi in a renal transplant recipient. Singap Med J. 2014;55(4):e64-6.

18. Girard C, Dereure O, Rispail P, Durand L, Guilhou JJ. Subcutaneous phaeohyphomycosis due to Pyrenochaeta romeroi in a patient with leprosy. Acta Derm Venereol. 2004;84(2):154-5.

19. Ocampo MA, Kanitakis J, Bienvenu AL, Chauvet C, Euvrard S. Phaeohyphomycosis caused by Pyrenochaeta romeroi mimicking a plantar wart in a kidney transplant recipient. Transpl Infect Dis. 2012;14(6):E173-4.

20. Borman AM, Linton CJ, Miles S-J, Johnson EM. Molecular identification of pathogenic fungi. J Antimicrob Chemother. 2008;61(Suppl 1):i7-12.

21. Borman AM, Campbell CK, Linton CJ, Bridge PD, Johnson EM. Polycytella hominis is a mutated form of Scedosporium apiospermum. Med Mycol. 2006;44(1):33-9.

22. Clinical and laboratory Standards Institute. Reference method for broth dilution antifungal susceptibility testing of filamentous fungi; Approved Standard-Second EditionDocument M38-A2. Pennsylvania; 2008.

23. Borman AM, Desnos-Ollivier M, Campbell CK, Bridge PD, Dannaoui E, Johnson EM. Novel taxa associated with human fungal black-grain mycetomas: Emarellia grisea gen. nov., sp. nov., and Emarellia paragrisea sp. nov. J Clin Microbiol 2016 [ahead of print].

24. Singh N, Chang FY, Gayowski T, Marino IR. Infections due to dematiaceous fungi in organ transplant recipients: case report and review. Clin Infect Dis. 1997;24(3):369-74.

25. Vermeire SEM, de Jonge H, Lagrou K, Kuypers DRJ. Cutaneous phaeohyphomycosis in renal allograft recipients: report of 2 cases and review of the literature. Diagn Microbiol Infect Dis. 2010;68(2):177-80.

26. Armstrong-James D, Teo IA, Shrivastava S, Petrou MA, Taube D, Dorling A, et al. Exogenous interferon- $\gamma$ immunotherapy for invasive fungal infections in kidney transplant patients. Am J Transplant. 2010;10:1796-803.

27. Perfect JR, Alexander BD, Schell WA. Phaeohyphomycoses (brown-black moulds). In: Kauffman CA, Pappas PG, Sobel JD, Dismukes WE, editors. Essentials of clinical mycology. 2nd ed. New York: Springer; 2011. p. 305-17.

28. Ahmed SA, de Hoog GS, Stevens DA, Fahal AH, van de Sande WWJ. In vitro antifungal susceptibility of coelomycete agents of black grain eumycetoma to eight antifungals. Med Mycol. 2015;53(3):295-301. 